\title{
Educação integral uma escola inclusiva: na perspectiva de ciclo de formação humana
}

\author{
Integral education an inclusive school: froom the perspective of the human training cycle \\ La educación integral uma escuela inclusiva: desde la perspectiva del ciclo de formação humana
}

Recebido: 17/07/2021 | Revisado: 25/07/2021 | Aceito: 27/07/2021 | Publicado: 03/08/2021

\author{
Vania Piau Santana Campos \\ ORCID: https://orcid.org/0000-0003-0915-8261 \\ Universidade de Cuiabá, Brasil \\ E-mail: vaniaeduca@gmail.com \\ Cilene Maria Lima Antunes Maciel \\ ORCID: https://orcid.org/0000-0003-4606-802X \\ Universidade de Cuiabá, Brasil \\ E-mail: cilenemlamaciel@gmail.com
}

\begin{abstract}
Resumo
O presente artigo, constitui-se de um delineamento da pesquisa de Mestrado do Programa PPGEn, UNIC-IFMT, em um processo parcial, que aborda o ciclo de formação humana na rede municipal de Educação de Cuiabá e a relação com a Base Nacional Comum Curricular. O objetivo pricinpal foi compreender o processo de fragmentação e das rupturas existentes no desenvolvimento das práticas de ensino-aprendizagem. Nesse sentido, o estudo constituiu-se em uma pesquisa participante, onde, estabeleceu-se um roteiro de entrevista, que foi usado como instrumento para a análise de dados. As entrevistas foram com professores do ensino fundamental I. Fizeram parte da pesquisa, três escolas de Cuiabá. A investigação caminhou em um desvelar das rupturas e fragmentos existentes dentro do ciclo de formação humana, nos aspectos teóricos e práticos, do saber prévio do professor, analisando o currículo em relação a realidade cultural e social do educando, dentro de um tempo-espaço. Portanto, essa pesquisa visou compreender, como acontece o processo de ensino-aprendizagem, nas respectivas escolas entrevistadas, respeitando os seu direito de aprendizagem, atendendo assim uma educação integral, respaldada pela BNCC. Sabe-se que esse indivíduo faz parte de uma pluralidade, que deve ser introduzida no processo de ensino-aprendizagem, tornando esse saber significativo e prazeroso. Os resultados parciais da pesquisa evidenciam, que o fazer pedagógico do professor precisa ser melhor compreendido no tempo-espaço que o aluno encontra-se inserido, esse processo necessita de uma reflexão em relação aos níveis diferenciados em sala de aula, respeitando o tempo-espaço do sujeito da ação pedagógica, em uma construção integral.
\end{abstract}

Palavras-chave: Ensino; Tempo-espaço; Educação integral; Direito de aprendizagem.

\begin{abstract}
This article consists of an outline of the Master's research of the PPGEn Program, UNIC-IFMT, in a partial process, which addresses the cycle of human formation in the municipal education network of Cuiabá and the relationship with the Common National Curricular Base. The main objective was to understand the fragmentation process and the existing disruptions in the development of teaching-learning practices. In this sense, the study consisted of a participatory research, where an interview script was established, which was used as an instrument for data analysis. The interviews were with teachers from elementary school I. Three schools in Cuiabá were part of the research. The investigation went on to unveil the ruptures and fragments existing within the human formation cycle, in the theoretical and practical aspects, of the teacher's previous knowledge, analyzing the curriculum in relation to the cultural and social reality of the student, within a time-space. Therefore, this research aimed to understand, as the teaching-learning process takes place, in the respective interviewed schools, respecting their right to learning, thus attending an integral education, supported by the BNCC. It is known that this individual is part of a plurality, which must be introduced in the teaching-learning process, making this knowledge meaningful and pleasurable. The partial results of the research show that the teacher's pedagogical practice needs to be better understood in the time-space that the student is inserted in, this process needs a reflection in relation to the different levels in the classroom, respecting the time-space of the subject of the pedagogical action, in an integral construction.
\end{abstract}

Keywords: Teaching; Time-space; Integral education; Right of learning.

\section{Resumen}

Este artículo es un esbozo de la investigación del Programa de Maestría del Programa PPGEn, UNIC-IFMT, en un proceso parcial, que aborda el ciclo de formación humana en la red educativa municipal de Cuiabá y la relación con el Currículo Base Común Nacional. El objetivo principal fue comprender el proceso de fragmentación y las rupturas que existen en el desarrollo de las prácticas de enseñanza-aprendizaje. En este sentido, el estudio consistió en una investigación participante, donde se estableció un guión de entrevista, que se utilizó como instrumento para el análisis 
de datos. Las entrevistas fueron con maestros de la escuela primaria I. Tres escuelas de Cuiabá fueron parte de la investigación. La investigación procedió a develar las rupturas y fragmentos que existen dentro del ciclo de la formación humana, en los aspectos teóricos y prácticos, de los conocimientos previos del docente, analizando el currículo en relación con la realidad cultural y social del alumno, dentro de un marco espacio de tiempo. Por lo tanto, esta investigación tuvo como objetivo comprender cómo ocurre el proceso de enseñanza-aprendizaje en las respectivas escuelas entrevistadas, respetando su derecho al aprendizaje, brindando así una educación integral, apoyada por la BNCC. Se sabe que este individuo forma parte de una pluralidad, la cual debe ser introducida en el proceso de enseñanza-aprendizaje, haciendo que este conocimiento sea significativo y placentero. Los resultados parciales de la investigación muestran que la práctica pedagógica del docente necesita ser mejor comprendida en el tiempo-espacio en el que se inserta el alumno, este proceso necesita una reflexión en relación a los niveles diferenciados en el aula, respetando el tiempo-espacio de el sujeto de la acción pedagógica, en una construcción integral.

Palabras clave: Docencia; Tiempo-espacio; Educación integral; Derecho a aprender.

\section{Introdução}

A educação no Brasil no final do século XX e início do século XXI, vem apresentando mudanças estruturais significativas, a Lei 9.394/96, deixa claro que a educação, não se restringe apenas dentro dos muros da escola, pelo contrário, estabelece: Art. $1^{\circ}$ que "A educação abrange os processos formativos, que se desenvolve na família, na convivência humana, no trabalho, nas instituições de ensino e pesquisa, nos movimentos sociais e organizações da sociedade civil e nas manifestações culturais".

Nesse sentido, a Lei de Diretrizes e Bases de 1996, diz que a educação pode ser desenvolvida de vários modos, esses caminhos que se interligam a educação-educando contempla um dinamismo constitutivo, contudo em tempos remotos esses olhares precisam ser revistos e compreendidos de formas diferentes, entendendo que outros sentidos necessitam ser aflorados com novas sensibilidades, e que o mundo virtual não substitui o presencial, pelo contrário amplia os saberes, quando de fato, existe uma democratização ao acesso dessas ferramentas.

Um dos desafios a serem superados conforme Arroyo (1999) e a grande problemática dos avanços apresentados na educação, na implantação dos ciclos de formação humana, se esquecendo de rever todo o referencial nas formações iniciais, bem como nas formações continuadas, pois o tradicionalismo encontra-se enraizado em sua estrutura acadêmica, além disso no chão da escola e no fazer pedagógico, que ainda retrata uma pedagogia reprodutiva, sem uma formação que apresentasse todo esse momento histórico de implantação dos ciclos:

Toda nova organização do trabalho educativo traz consequências sérias em todos os níveis, sobretudo em nossa autoimagem profissional. As pesquisas e a reflexão teórica se voltam para as propostas pedagógicas que estão implementando os ciclos de formação. A formação de profissionais da Educação Básica se pergunta que tipo de profissional está sendo requerido, ou melhor, está se formando nessa modalidade de organização do trabalho pedagógico. (Arroyo, 2011, p. 145).

Além disso, o tempo e espaço, nesse novo modelo é constituído a partir do objeto de estudo que é o próprio aluno, considerando o tempo necessário, um conhecimento não fragmentado, obedecendo não mais um calendário rígido e institucional, mas a uma concepção temporal que permita essa efetivação (Lima 1998). Logo, esse aluno ao longo do ciclo da infância, poderá desenvolver os conceitos básicos da leitura, escrita e das quatro operações. Sabe-se que cada um tem a sua construção efetiva e que por certo, cada ciclo irá fortalecer os conceitos básicos que esse sujeito precisa desenvolver ao longo da educação básica.

Devido a toda essa reestruturação o Município de Cuiabá/MT, se organizou-se em Ciclo de Formação Humana conforme Lei 11.274/2006, que acrescenta um ano na etapa inicial da alfabetização e a definição do "ciclo da infância" com três anos de duração, enfatizando que este é um período dedicado à alfabetização e ao letramento, ao desenvolvimento das diversas expressões e ao aprendizado das áreas de conhecimento (Brasil, 2008). 


\section{Base Nacional Comum Curricular: e a parte diversificada.}

O desafio foi lançado, gerar uma educação que contemple o educando em sua integralidade. Segundo Tardif (2014), a educação precisa ter um olhar holístico, não sendo um saber fragmentado, nem compartimentado, mas sim vários saberes, compreendendo que a construção do conhecimento será efetiva, quando levar em consideração todos esses aspectos. (Capra, 2006).

A Base Nacional Comum Curricular, apresenta em seu texto uma parte diversificada, conforme o que está no art. 26 da LDB 1996 que determina:

Uma base comum a todos a ser complementada em cada sistema de ensino, bem como nos estabelecimentos escolares, por uma parte diversificada, que contemple as características regionais e locais da sociedade, da cultura, da economia e dos educandos, a fim de contemplar a pluralidade cultural existente em nosso país. (LDB,9394/96, art.26).

A BNCC (2017), determina que cada Estado deverá construir a sua parte diversificada, respeitando cada região e realidade local dos municípios, sabe-se, que esse olhar real e local precisa ser compreendido por todas as partes que envolve a educação, profissionais da educação, professores, alunos e comunidade. Em Indagações sobre currículo, Arroyo (2007) propõe vários questionamentos, entre eles:

Que organização dos currículos e da escola tornará nosso trabalho mais humano? [...] que lógicas, concepções, valores regem, legitimam essa organização? São igualitárias, democráticas, inspiradas no referente político da garantia do direito de todos ao conhecimento, à cultura, a formação como humanos? São lógicas que permitem a humanização do trabalho dos profissionais das escolas? Que igualam ou hierarquizam os docentes? (Arroyo, 2007, p.19).

Portanto quais lógicas devem ser questionadas? Quais os valores que de fato são necessários ser construídos na identidade educador-educando?

Conforme Sacristán (2001), a diversificação curricular, não é um desenho ou um molde especifico para cada grupo, ou ciclo, mas pensar o currículo diversificado na experienciação dos estudantes, saindo da homogeneidade a heterogeneidade. A escola só é igual para todos, quando essa escola enxerga a toda essa diversidade e coloca o personagem da ação como protagonista do processo de ensino-aprendizagem.

A escola reflexiva, em seu papel social de preparar o sujeito para a vida como cidadão, ressalta que o papel da escola vai além dessa preparação, a escola é a própria vida que já está sendo construída em um local de vivência da própria cidadania, como também a escola é um lugar de identidades diversas e o fazer cidadão, vai-se construindo em um determinado espaço, tempo e contexto, sendo a escola um dos meios mais importantes, de espelhar identidades, em outro espaço não seriam também contempladas. (Alarcão 2001).

O conhecimento deve ser compartilhado entre educador-educando, segundo Freire (2018) não deve existir uma hierarquia, e sim uma troca, para isso deve-se repensar o currículo em novos tempos e espaços, enxergar os autores ocultos que também fazem parte do currículo, mas são ignorados em situações sociais, financeiras, culturais e físicas, refletindo assim, em dificuldades na sistematização de sua aprendizagem, devido a todos esses fatores citados.

Quando se fala em diversidade cultural, entende-se, que a identidade de educador é construída no contexto social, que faz parte de um fenômeno que atravessa tempo e espaço, tornando-se mais complexa a cada tempo-histórico que a humanidade vai se constituindo, sendo que nenhuma identidade é constituída no isolamento (Gomes, 2008).

Contudo, a Política Educacional do municipio de Cuiabá, na proposta da Escola Cuibana de 2019, se estrutura em uma parte diversificada, dentro da realidade histórico-cultural do nosso povo, permeando toda vivência, no linguajar, nas tradições religiosas, nas danças típicas, na gastronomia e no artesanato, tanto nas escolas rurais-ribeirinhos, como nas escolas urbanas, respeitando a cada identidade linguística e cultural, em uma Base curricular comum para todos, mas também, com uma contextualização real, partindo do lugar de fala de cada sujeito da ação. 


\section{Os direitos de aprendizagem um direito de todos.}

Esse marco é apresentado nas Diretrizes Curriculares de 2013, fortemente associado ao exercício da cidadania que por sua vez está atrelado ao exercício dos direitos civis, políticos e sociais. O direito civil está associado ao direito constitucional do país em sua privacidade, liberdade de opinião, de crença, esses direitos contemplam a todas as camadas brasileiras. O Art. 205 da Constituição Federal de 1988, diz: “A educação, é direito de todos e dever do Estado e da família, será promovida e incentivada com a colaboração da sociedade, visando o pleno desenvolvimento da pessoa, seu preparo para o exercício da cidadania e sua qualificação para o trabalho". Essa proposta constitucional, deixa claro em suas linhas o direito a educação e ao pleno desenvolvimento da pessoa humana, em todos os aspectos: intelectual, físico, emocional e social.

Nesse contexto histórico-social, as Diretrizes Curriculares de 2013, registra o direito à diversidade, que tem sido muito abordado, não só como um direito social, mas algo que vai além, no aspecto individual, assegurando o seu lugar de fala dentro de um grupo específico, das múltiplas identidades que estão sendo constituída no chão da escola, e que precisa ser reconhecida em seus direitos e contextos específicos.

Como também o direito político, que oportuniza o sujeito nas decisões importantes na construção histórica do Brasil, não sendo só um portador de direito, mais transformador de direitos, em novos direitos que contemplem a todos os envolvidos no processo, respeitando de forma democrática ao conjunto de indivíduos que fazem parte dessa esfera pública, que por muitas vezes possui opiniões e pensamentos divergentes, portanto, a postura dialógica deve ser o ponto socialmente político a ser desenvolvido pela educação.

Em seguida as Diretrizes apontam também, o direito social, que depende da ação do Estado para ser concretizado, e que está associado diretamente a melhorias sociais, que de certa forma oportunizam uma sociedade com condições de equidade social, entendendo que todos são iguais perante a lei, como diz a nossa Carta Magna de 1988.

\section{Uma escola inclusiva na concepção da pluralidade de saberes.}

O ciclo de formação humana, propõe uma escola inclusiva, entendendo que esse agrupamento possui sua especificidade física, cultural, social, intelectual, neurológica, étnica, gênero e religião, todos de uma certa forma possui sua singularidade. Essa inclusão vem propondo um novo modelo de escola, um espaço com significado dentro de cada sujeitoprotagonista, uma escola reflexiva que contextualiza suas práticas e dialoga com essa diversidade, com um trabalho focado em grupos heterogêneos, um trabalho individual, porém focado no coletivo em uma perspectiva colaborativa (Alarcão, 2001).

A educação inclusiva trouxe muitos debates e discussões em todas as esferas políticas da educação, Alarcão (2001), apresenta uma escola para todos, com equidade social, desconstruindo paradigmas e construindo um novo paradigma norteado pela diversificação, reflexividade e eficácia.

Como padroniza-los? Como vestir a todos com uma mesma roupagem? Como garantir o direito a aprendizagem se o sujeito não é visto de maneira individualizada? Para que cada aluno se desenvolva dentro de sua especificidade ele precisa ser entendido dentro dessa concepção

O incômodo é que há inúmeros alunos em uma aula. Ora, uma situação-padrão consegue excepcionalmente ser ótimo para todos, porque eles não têm o mesmo nível de o saber, os mesmos interesses, os mesmos recursos e maneiras de aprender. Diferenciar e romper com a pedagogia frontal - a mesma lição, os mesmos exercicios para todos -, mas é, sobretudo, criar uma organização do trabalho e dos dispositivos didáticos que coloquem cada um dos alunos em uma situação ótima, priorizando aqueles que tem mais a aprender. Saber conceber e fazer com que tais dispositivos evoluam é uma competência com a qual sonham e a qual constroem pouco a pouco todos que pensam que o fracasso escolar não é uma fatalidade, que todos podem aprender. (Perrenoud, 2000, p. 55).

A homogenia precisa ser rompida, a escola fracassou por décadas dentro desse sistema fragmentado, sequenciado e engessado. Segundo Perrenoud, (2000), a escola precisa propor novas alternativas de aprendizagens. Um aprendizado 
sistêmico e que atenda essa heterogenia, a caminhos ser reconstruídos, dentro de uma flexibilidade de tempo-espaço, ampliados a um currículo que seja construído no fazer pedagógico. (Pimenta, 2012).

Partindo das vozes dos alunos as aulas tornam representativas e com significados reais ao seu contexto social, dar voz e vez, entender qual será o ponto de partida que o professor precisará conduzir os conteúdos e leva-los ao um objetivo de aprendizagem (Perrenoud, 2000).

Sabe-se que para abranger essa multiplicidade dentro de uma única sala de aula, necessitará desenvolver várias competências, tem do que desenvolver de maneira sistêmica essa heterogeneidade, precisa ser estruturado em um espaçotempos ampliados, ter um olhar atento principalmente aos alunos com dificuldade de aprendizagem seja intelectual ou física e assumir um papel de cooperação mútua entre todos os alunos. (Perrenoud, 2000).

\section{Metodologia}

Esta produção, transcorreu num procedimento de investigação qualitativa exploratória, entendendo que o questionamento nas Ciências Sociais é apresentado de maneira ampla, pois pretende conferir ou concatenar os referências do âmbito do estudo, acerca de sua expressividade e não se inquieta em esclarecer uma única premissa, no entanto, busca descobrir as causas comunitárias que ainda são pouco conceituadas, e no desfecho, tende adequar o levantamento realizado a uma nova proposta de ensinar em uma análise focada aquela realidade social. (Minayo, 2011).

A pesquisa abrange uma investigação minuciosa, onde confronta a realidade do sujeito da pesquisa, são levantados dados, informações, estudos, comprovações, baseando em um estudo problema, engloba aí a realidade em lócus com o conhecimento teórico. Com isso pode-se embasar e confirmar junto aos teóricos a relação do processo pesquisado da prática com a teoria. (Ludke \& André, 2020). Conforme as autoras, a pesquisa traz a sua vertente humana e social, e com isso, imprescindível os valores morais, humanos, sociais que por si só irá conduzir as falas dos entrevistados.

A pesquisa qualitativa em educação segundo Bogdan e Biklen (1994) apresentam características básicas, como: Lócus da pesquisa e o pesquisador em seu olhar como observador e captador de todo o processo natural do ambiente; os levantamentos são descritivos e detalhados; O interesse no processo se torna mais significativo; a importância dos valores emocionais e sociais dos entrevistados, são relevantes para o pesquisador; o pesquisador não busca seguir um processo de persuasão.

Este estudo, teve como base a pesquisa exploratória, que segundo Gil (2008) ajuda a promover uma maior aproximação com o objeto de estudo, familiarizando ao problema em questão. Esse método pode ser realizado de várias formas como, entrevistas e levantamentos bibliográficos. Gil (2008), apresenta que todos esses métodos são procedimento técnico muito importante, pois levanta indagações e reflexões dos comportamentos das pessoas entrevistadas, levando em consideração o problema de estudo, para assim obter resultados inerente e chegar a uma determinada conclusão dentro do grupo pesquisado.

A pesquisa participante é apresentada nesse estudo, segundo Brandão (1999) um envolvimento com o sujeito da ação, levando em consideração seus anseios, potencialidades, dúvidas e medos. Não existe uma padronização, não é estática, pois existe um envolvimento dos sujeitos e isso corrobora na flexibilidade, como instrumento mediador para com que o pesquisador tenha um olhar atento ao processo da pesquisa.

Assim, tendo em vista a possibilidade de investigar, e propor subsídios teóricos para ampliação destes estudos, que são relevantes para a melhoria das práticas educativas pautadas na BNCC e na Política Pública Educacional do município de Cuiabá, na proposta de ciclo de formação humana, a método utilizado foi a pesquisa participante, conforme Brandão (1999), conceitua esse modelo de pesquisa, pautado em um aprofundamento da realidade social, em que os envolvidos nesse processo 
socializam em uma reflexão de sua própria realidade. Assim sendo, a pesquisa participante, não trata apenas de um levantamento de dados é também, uma ação coletiva promovendo a participação da comunidade.

Dessa forma, O instrumento de pesquisa foi um roteiro de entrevista, que conforme Ludke e André (2020), caracteriza um instrumento basilar para a coleta de dados, sendo uma das principais técnicas de trabalho utilizadas nas ciências sociais, apresenta importante papel não apenas na pesquisa científica, mas na visão humana. Esse instrumento foi usado com professores do ensino fundamental I, de duas escolas da rede municipal de Cuiabá e uma escola da rede estadual de Cuiabá, sendo um total de 15 participantes, seis professores, três coordenadores e três diretores.

A análise de conteúdo foi fundamentada em Bardin, (2016) onde conceitua os dados e para uma categorização organizada e agrupadas em classes de elementos relevantes, tornando apresentando dados qualitativos, que relaciona um agrupamento de técnicas de pesquisa que busca sentido aos conteúdos levantados.

A análise de conteúdo aparece como um conjunto de técnicas de análise das comunicações, que utiliza procedimentos sistemáticos e objetivos de descrição do conteúdo das mensagens. [...] a intenção da análise de conteúdo é a inferência de conhecimentos relativos às condições de produção, ou inferência que recorre a indicadores. (Bardin, 2016, p. 38).

Bardin (2016) o objetivo do método é propor técnicas que concentre ideias na proposta de construir as categorias, para facilitar e apresentar os pontos relevantes da pesquisa. O método atua em avaliar de maneira minuciosa e condensada toda a estrutura do texto, para assim fatiar de maneira quantitativa as partes mais relevantes do objeto de pesquisa

Dessa forma, o pesquisador utilizará de tal dispositivo, com o intuito de extrair, informações, e posteriormente tais informações, serão classificadas pelo processo de codificação, que são ferramentas utilizadas dentro do método de análise de conteúdo. Ademais, no conjunto das técnicas da análise do conteúdo, se aplica a técnica de categorização que é considerada cronologicamente a mais antiga, sendo, portanto na prática a mais utilizada.

$\mathrm{Na}$ análise de conteúdo, "a análise categorial tem servido de base para descrever as principais fases de uma análise de conteúdo" (Bardin, 2016, p. 153). Com isso, a respeito de tal método, a autora ainda enfatiza que:

A codificação corresponde a uma transformação-efetuada segundo regras precisas - dos dados brutos do texto, transformação esta que, por recorte, agregação em enumeração, que permite atingir uma representação do conteúdo, ou da sua expressão, susceptível de esclarecer o analista acerca das características do texto, que podem servir de índices. (Bardin, 2016, p. 103).

\section{Resultados e Discussão}

Pontua-se, que o presente estudo, apresenta um resultado parcial, de entrevistas com professores, coordenadores e diretores, em escolas organizadas por ciclos de formação humana, com uma prática que muitas vezes não considera esse tempo/espaço de construção do aluno. Conforme conceitua Perrenoud (2000), sair de uma visão frontal, homogênea e adequar-se à realidade cognitiva do sujeito.

Arroyo (1999) apresenta uma grande problemática dos avanços educacionais, em destaque aqui, o ciclo de formação humana, essa proposta não caminhou junto com as formações iniciais, pois o tradicionalismo continua impregnado em sua prática docente. Os tempo-espaços são outros, os alunos do século XXI vem desafiando a nossa prática pedagógica, nossos valores, identidades profissionais e competências que precisam ser desenvolvidas na figura do educador.

$\mathrm{O}$ fragmento abaixo, pontuam dificuldades de uma prática que atenda essa realidade, respeitando o tempo e espaço do aluno: 
Hoje, falta a gente compreender, que muitas das nossas práticas enraizadas no nosso dia a dia em sala de aula, ainda são práticas que nós aprendemos quando fomos alfabetizados, né, e eu vejo que hoje falta essa compreensão, de como acontece esse processo de aprendizagem, né, a gente precisa, nós, enquanto alfabetizadoras e professoras, dominar mais os conceitos e teorias dos níveis e até o processo de aprendizagem que esse aluno passa, e entender todo esse contexto de tempo-espaço do aluno. (Professora $1 \mathrm{~K}$ ).

As mudanças pedagógicas precisam efetivar-se em uma visão não mais hierárquica-vertical, mas humanizadahorizontal, entendendo que cada ser humano possui sua singularidade, com crescimento cognitivo distinto, independentemente da idade biológica, pensar o ser humano na sua particularidade, considerando todas suas fases, dentro de sua pluralidade cultural. (Wallon, 2007).

Outro desafio, que eu me deparo é a maturação da criança, com relação ao projeto de alfabetização, e com isso, precisamos ter um entendimento de como trabalhar essas atividades respeitando essa maturação, muitas crianças não estão maduras ainda, mesmo em idades referenciadas da política Cuiabana, entendendo que a alfabetização não tem uma idade certa para acontecer, mesmo sendo a idade que é normatizada essa construção, mesmo assim, vem sem maturação nenhuma para isso, né, já é um fator que gera um certo trabalhinho ali, em fazer com que essa alfabetização prossiga na construção da alfabetização nos anos iniciais, e ai, a gente percebe a necessidade de compreender esse tempo-espaço que o aluno está. (Professora 2D).

O ciclo de formação humana, assume uma característica inclusiva, pois conceitualmente, propõe um trabalho diferenciado, saindo do modelo homogêneo e buscando uma prática heterogênea, com isso, faz-se necessário um novo olhar, criar uma escola reflexiva, propondo e construindo um sujeito que faz parte do seu próprio processo educativo, com práticas dialógicas. (Alarcão,2001). As professoras abaixo, apontam toda essa realidade, e a necessidade de construir planejamentos heterogêneos, e com práticas pedagógicas, que comunguem com a realidade específica do aluno, porém apresenta as dificuldades:

Uma da dificuldade que eu percebo primeiramente é que tem alunos que estão em níveis diferenciados de ensino, então, fazer um planejamento que venha atender a todos os alunos é um pouco complicado, daí temos que elaborar mais de um planejamento, para atender as dificuldades dos alunos e tem que ter toda uma estratégia, pois normalmente são alunos agitados, [...] que exige uma dinâmica maior, é (risos) (Professora 3A).

Arroyo (2007) reforça esse conceito de superar um modelo padronizado de atividades e métodos, e rever a sua identidade como educador, pois os valores são outros e o professor precisa gerar novas competências em sua identidade pedagógica, para que seja construído novas habilidades de um fazer pedagógico propositivo.

Eu percebo uma das maiores dificuldades, são os níveis diferenciado dos alunos em uma mesma sala [...] a gente trabalhar as atividades, tenta fazer diferenciado, dentro dos níveis do aluno que a gente encontra, mas muitas vezes ainda não é eficiente [...] e muitas vezes o que você vai encontrar em um segundo ano, por exemplo é, um aluno que ele mal reconhece, e, e, o alfabeto, ele está começando o processo de conhecimento de alfabetização, e você vai encontrar alguns, que no terceiro bimestre vai estar lendo e outros estarão iniciando o processo silábico, então o que acontece, você tem que ter uma visão de trabalhar esses níveis diferenciados, para respeitas esse tempo e espaço do aluno, mas colocar isso em prática não é fácil. (Professora 4R).

Arroyo (2007), destaca a importância de um olhar diferenciado sobre as vivências do aluno, em qual contexto está inserido, essa visão amplia a identidade do professor, em perceber o aluno em sua plenitude, considerando o seu tempo e o espaço. As professoras abaixo, discorrem em sua fala a influência familiar no desenvolvimento cognitivo do aluno:

Bom, a maior dificuldade que eu percebo, eu como professora alfabetizadora, embora, a criança já viva em um mundo de letra de palavras, porém essa cultura da leitura de livros, da intencionalidade de aprendizagem ou de leitura não é incentivada pela família, esse contexto familiar reflete dentro de sala [...] quando essa criança entra na 
sala de aula, sem esse contexto, essa vivência, daí, praticamente você tem que começar do zero, levar essa criança a refletir sobre a escrita a leitura, agora a criança que já vem com essa vivência fica mais fácil desenvolver a conhecimento, e é claro, que existem outras dificuldades relacionadas ao cognitivo da criança, por isso a necessidade de entender toda essa realidade desse saber do aluno (Professora 5T).

Uma das dificuldades maiores é o auxílio familiar, que já era difícil no presencial, e agora no on-line, ficou bem mais complicado, pois no contexto familiar, esse desenvolvimento escolar fica precário e sem falar do cotidiano que as crianças estão envolvidas, muitas vezes sem obrigações ou sem a devida rotina escolar, ficando por conta do dia a dia da casa. (Professora 6L).

Um ponto que tem sido considerado pelos professores, nesta amostra parcial é o que está normatizado na BNCC (2017) e nas Políticas Públicas do Município de Cuiabá (2019), que vem propondo um currículo que atenda a realidade do sujeito em sua integralidade e diversidade de saberes. Arroyo (2007) apresenta vários questionamentos, de um currículo que atenda de fato a realidade do sujeito: Que organização dos currículos e da escola tornará nosso trabalho mais humano? A professora $7 \mathrm{M}$ e a $8 \mathrm{R}$ relatam como acontece essa aplicabilidade:

Os conteúdos selecionados são dentro da realidade cognitiva que o aluno se encontra, porém muitas vezes, não está dentro da proposta das etapas de alfabetização. A gente trabalha com base nas referências curriculares da Escola Cuiabana, que é claro, está relacionado com a BNCC, evidenciando as habilidades do $1^{\circ}$ ano e do $2^{\circ}$ ano do ensino fundamental I. (Professora 7M).

Sim, o município tem um projeto, que é o PROAC, que quer dizer, Programa de Alfabetização Cuiabana, o projeto é baseado na BNCC, e lá a gente tem um material, muito rico de alfabetização, que ele traz textos, cartazes, tudo dentro desse momento que estamos vivendo, nesse contexto da pandemia [...] em uma vivência que eles estão inseridos, com textos diversificados, em diferentes gêneros, de uma forma que um conteúdo acaba casando com o outro, isso enriquece muito o conhecimento da criança em relação aos textos e gêneros. (Professora $8 R$ ).

Devido a implantação e implementação da BNCC (2017) no chão da escola, toda a estrutura organizacional e física foi necessária uma adequação, e a lei 11.274/2006, que estabelece o ciclo de formação humana, normatiza esse funcionamento. Uma das diretoras entrevistadas, discorre em sua fala, sobre as políticas de alfabetização estabelecidas pelo município de Cuiabá e as estratégias criadas pela SME, para consolidar toda essa realidade no âmbito da alfabetização:

Como gestora, não enfrentei resistência nas implementações junto aos professores, tendo em vista, que a política recém nascida, a Escola Cuiabana, a gente está aprendendo e conhecendo, para estar trabalhando, mas a Secretaria tem subsidiado os professores, com as devidas formações, então assim, não é simplesmente cumpra-se, eles estão dando mecanismo para que os professores possam estar trabalhando, para o professor aprender de que forma fazer, isso é muito importante, para que se tenha um bom resultado da alfabetização até o segundo ano, que anteriormente a construção seria até o terceiro ano, como houve essa mudança com a BNCC e ai as coisas se encaminharam para um novo formato. (Diretora $M$ ).

Os professores atualmente, estão tendo uma outra percepção dentro da quantidade de formação que o município tem oferecido, a rede está tendo uma boa aceitação na política de alfabetização proposta pelo município, a participação é bem efetiva. Essa política de alfabetização vem com uma capacitação envolvente e bem estruturada como o PROAC, a escola da inteligência que vem somando no aspecto sócio emocional dos nossos alunos. Os professores são muito bem assistidos juntamente com a coordenação, assessoria e a própria Secretaria. (Diretora E).

Dessa forma, o currículo deve ser construído em uma amplitude de olhares minuciosos do fazer pedagógico, para que as diferenças agreguem valores diversos aos seus pares e se sintam pertencentes, e aos que não conhecem que compreendam todo o processo histórico-cultural daquela etnia. Essa heterogenia que impera no chão da escola precisa ser retratada e estruturada aos currículos, de modo que esse trato pedagógico seja desenvolvido pelo educador, em um olhar que permeie a sensibilidade do educando. 
Agora na Figura 1 estaremos fazendo as representações das falas que foram mais relevantes na pesquisa, a partir disso foram levantadas as especificações mais relevantes da categoria, de forma a detalhar as categorizações consonante especificações representadas abaixo:

Figura 1 - Categorias de análise.

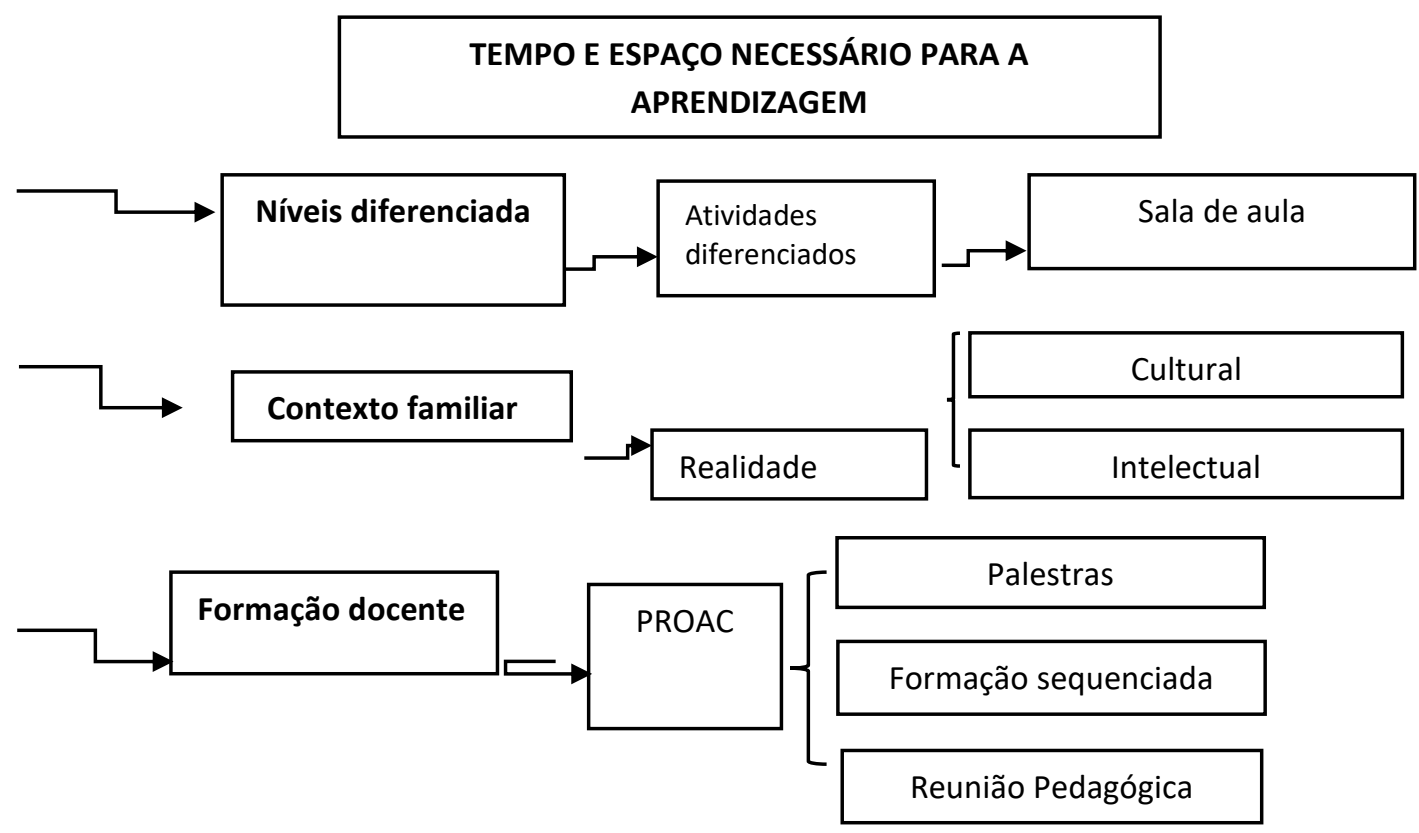

Fonte: Da pesquisa (2021).

$\mathrm{Na}$ Figura 2, segue as representações por tópicos específicos, que neste caso são apresentados os níveis diferenciados que existe em uma mesma sala de aula:

Figura 2 - Representação da categoria: Níveis diferenciados.

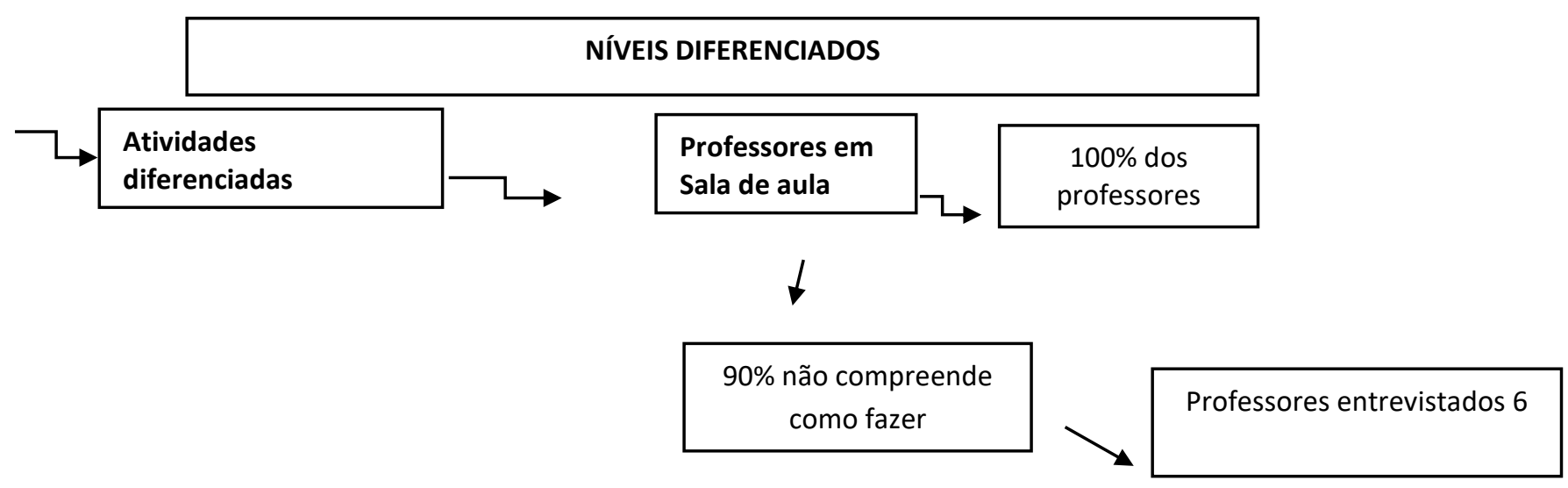

Fonte: Da pesquisa (2021).

A Figura 2 apresentadas pelas amostras dos entrevistados da pesquisa, em sua relevância, nas falas, suas maiores dificuldades tem sido desenvolver atividades ou uma prática que contemple a todos os alunos, pois normalmente em uma sala de aula, estão inseridos alunos com níveis diferenciados, Quando foram indagados sobre as dificuldades no processo de 
alfabetização, os professores que fizeram parte da amostra em sua maioria apresentar a dificuldade de propor e como trabalhar esse processo diferenciado:

[...] eu percebo uma das maiores dificuldades, são os níveis diferenciado dos alunos em uma mesma sala [...] a gente trabalhar as atividades, tenta fazer diferenciado, dentro dos níveis do aluno que a gente encontra, mas muitas vezes ainda não é eficiente [...]. (Professora 4R).

[...] enquanto alfabetizadoras e professoras, dominar mais os conceitos e teorias dos níveis e até o processo de aprendizagem que esse aluno passa, e entender todo esse contexto de tempo-espaço do aluno. (Professora 1 K).

[...], precisamos ter um entendimento de como trabalhar essas atividades [...]. (Professora 2D).

[...] Uma das dificuldades que eu percebo primeiramente é que tem alunos que estão em níveis diferenciados de ensino, então, fazer um planejamento que venha atender a todos os alunos é um pouco complicado [...] (Professora $3 A)$.

[...] dificuldades relacionadas ao cognitivo da criança, por isso a necessidade de entender toda essa realidade desse saber do aluno (Professora 5T).

[...]. os conteúdos selecionados são dentro da realidade cognitiva que o aluno encontra-se[...]. (Professora 7M).

Na Figura 3, segue as representações por tópicos específico, que neste caso apresenta a realidade no contexto familiar que o aluno está inserido:

Figura 3 - Representação da categoria: Contexto Familiar.

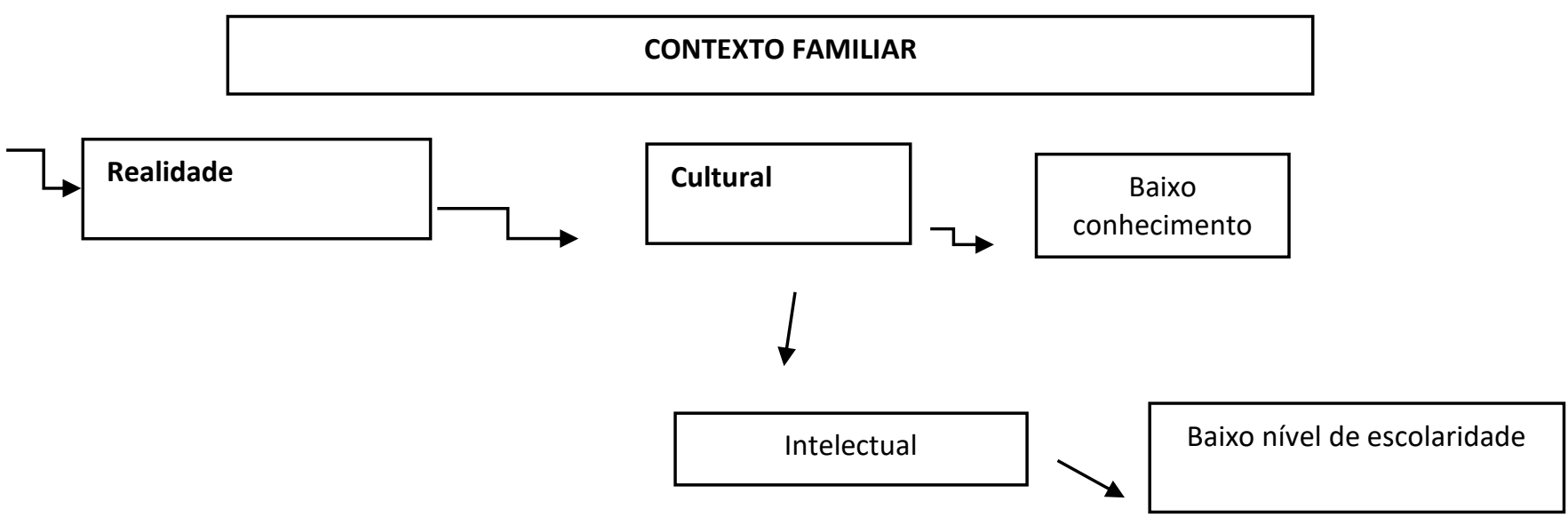

Dos entrevistados que abordaram a dificuldade familiar 2

Fonte: Da pesquisa (2021).

Da Figura 3 segue abaixo algumas falas dos entrevistados que abordaram dificuldades em relação a família e ao contexto familiar em que os alunos estão inseridos:

[...] Bom, a maior dificuldade que eu percebo, eu como professora alfabetizadora, embora, a criança já viva em um mundo de letra de palavras, porém essa cultura da leitura de livros, da intencionalidade de aprendizagem ou de leitura não é incentivada pela família, esse contexto familiar reflete dentro de sala [...]. (Professora 5T).

[...]Uma das dificuldades maiores é o auxílio familiar[...] (Professora 6L). 
Na Figura 4, segue as representações por tópicos específicos, que são as formações que a SME tem promovido aos professores de educação, com formações que atendam as orientações da BNCC em relação ao processo de alfabetização:

Figura 4 - Representação da categoria: Formação docente.

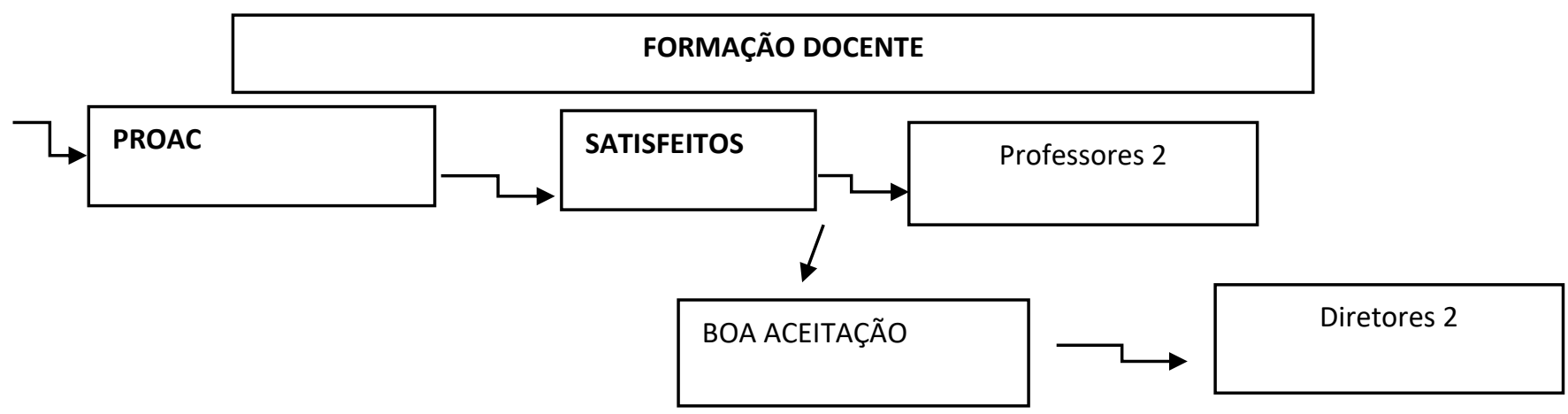

Fonte: Da pesquisa (2021).

Da representação da Figura 4 os professores e gestores que foram entrevistados e apresentados nessa amostra parcial, apresenta satisfação com a formação do PROAC que é o Projeto de Alfabetização da Escola Cuiabana, que faz parte da Política Educacional do município de Cuiabá. Segue abaixo algumas falas relevantes dessa formação de alfabetização

[...], e lá a gente tem um material, muito rico de alfabetização, que ele traz textos, cartazes, tudo dentro desse momento que estamos vivendo, nesse contexto da pandemia [...]. (Professora $8 R$ ).

. [...]A gente trabalha com base nas referências curriculares da Escola Cuiabana, que é claro, está relacionado com a BNCC, evidenciando as habilidades do $1^{\circ}$ ano e do $2^{\circ}$ ano do ensino fundamental I. (Professora $7 M$ ).

[...] Como gestora, não enfrentei resistência nas implementações junto aos professores, tendo em vista, que a política recém-nascida, a Escola Cuiabana, a gente está aprendendo e conhecendo, para estar trabalhando, mas a Secretaria tem subsidiado os professores, com as devidas formações[...] (Diretora $M$ ).

[...]os professores atualmente, estão tendo uma outra percepção dentro da quantidade de formação que o município tem oferecido, a rede está tendo uma boa aceitação na política de alfabetização proposta pelo município, a participação é bem efetiva. Essa política de alfabetização vem com uma capacitação envolvente e bem estruturada[...] (Diretora E).

\section{Considerações Finais}

A partir dos resultados preliminares, foram evidenciados pelos professores as dificuldades se trabalhar com atividades diferenciadas, pois dentro de uma mesma sala de aula existe níveis diferenciados. Os professores, em sua maioria, apresentam dificuldades no processo e na dinâmica de conduzir as atividades diferenciadas de modo efetivo, muitas vezes essas atividades diferenciadas acabam por não atingir a necessidade do aluno.

Nessa sequência, a ausência da família, foi um outro ponto destacado, muitas não participam desse processo, umas por omissão, outras por falta de conhecimento e muitas por falta de tempo.

Outro levantamento feito, foi na concepção de como está sendo realizada a formação na etapa de alfabetização pela SME, conforme as falas das gestoras e de algumas professoras entrevistadas, as formações têm sido diferenciadas e bem aceitas pelos professores, pois os materiais são ricos e contextualizado para esse momento, todas as sugestões e orientações são bem aplicadas em sala de aula, favorecendo o contexto que os alunos estão vivendo, porém ainda é algo que está sendo desenvolvido, e os professores estão aprendendo no fazer pedagógico. 
Dessa forma ao trabalhar na proposta de ciclo de formação humana, o professor terá que investir em sua capacitação continuada, bem como geral novas identidades que são necessárias para esse novo modelo educacional, rever toda a sua trajetória profissional, para que as competências primordiais para o professor sejam desenvolvidas de maneira plena a refletir no sujeito em sua integralidade, em todas as suas dimensões físicas, biológicas, psicológicas, sociais e culturais.

Recomenda-se, um estudo minucioso sobre a importância de geral competências emocionais nos profissionais da educação, para que de fato o professor possa construir de maneira efetiva as dez competências que estão preconizadas na BNCC. Bem como orienta-se uma pesquisa dentro das dificuldades de aprendizagem em uma visão metodológica que comtemple esse aluno em sua singularidade.

\section{Referências}

Alarcão, I. (2001). Escola reflexiva e nova racionalidade. Artmed.

Arroyo, G. M. (2007). Indagações sobre o currículo: Educandos e Educadores: seus direitos e o currículo. (Org.) Janete B, Sandra D. Pagel, Aricélia do Nascimento. Mistério da Educação, SEB.

Arroyo, G. M. (1999). Ciclo de desenvolvimento humano e formação de educadores. Educação \& Sociedade. $20(68), 143-161$.

Arroyo, M. G. (2011). Educador em diálogo com nosso tempo. Autêntica.

Bardin, L. (2016). Análise de conteúdo. Tradução: Luís Augusto Pinheiro. Edições 70.

Bogdan, R. C \& Biklen, S. K. (1994). Investigação qualitativa em educação: uma introdução à teoria e aos métodos. Porto Editora.

Brandão, C. R. (1999). Pesquisa participante. Ed. Brasiliense.

Brasil. (2017). Base Nacional Comum Curricular. Material de Referência Pedagógica: Educação Infantil, e Ensino Fundamental. presidência da república.

Brasil. Lei no 11.274, de 06 de fevereiro de 2006. Altera a redação dos artigos 29, 30,32 e 87 da lei n. 9.394/1996.Sitehttp//www.planalto.gov.br/ccivil-03/Ato2011 2014/2013/Lei/L12852.htmAndgt; Acesso em 11 de jan. 2020.

Brasil. (2016) [Constituição (1988) ] Constituição da República Federativa do Brasil: texto 112 constitucional promulgado em 5 de outubro de 1988. Brasília: Senado Federal, Coordenação de Edições Técnicas.

Brasil. (2013). Diretrizes Curriculares Nacional da Educação Básica: Material de Referência Pedagógica: Educação Básica. Brasília: MEC.

Capra, F. (2006). O Ponto de Mutação. Tradução: Álvaro Cabral. Cultrix.

Gil, A. C. (2008). Como elaborar projetos de pesquisa. Atlas.

Gomes, N. L. (2008). Indagações sobre Currículo: Diversidade e Currículo. (Org.) Janete B, Sandra D. Pagel, Aricélia do Nascimento. Brasília: Mistério da Educação, SEB.

Lima, E S. (1998). Escola em Ciclo de Formação: uma reorganização do tempo escolar.

Mato Grosso, (2000). Escola Ciclada de Mato Grosso: novos tempos e espaços para ensinar-aprender a sentir, ser e fazer. SEDUC.

Ministério da Educação. Conselho Nacional de Educação. Parecer CNE/CEB no 4/2008, de 20 de fevereiro de 2008 . Orientação sobre os três anos iniciais do Ensino Fundamental de nove anos. Diário Oficial da União, Brasília, DF, 10 jun. 2008a.

Minayo, M. C. de S. (2011). Pesquisa Social: teoria, método e criatividade. Vozes.

Perrenoud, P. (2008). Dez novas competências para ensinar. Tradução: Patrícia Chittoni Ramos. Artmed.

Pimenta, S. G. (2012). Saberes Pedagógicos e Atitudes Docentes. Cortez.

Políticas Educacionais da Secretaria de Educação de Cuiabá. (2019). Escola Cuiabana: cultura, tempos de vida, direitos de aprendizagem e inclusão.

Sacristan, José G. (2017). O currículo: uma reflexão sobre a prática. (Trad. Ernani F. da Fonseca Rosa. Penso.

Tardif, M. (2014). Saberes docentes e Formação Profissional. Vozes

Wallon, H. (2007). A evolução psicológica da criança. Martins Fontes. 